УДК 330.16:334.012.64

ПРОБЛЕМА РАЗВИТИЯ МОЛОДЕЖНОГО ПРЕДПРИНИМАТЕЛЬСТВА: ЭКОНОМИЧЕСКИЕ И ПСИХОЛОГИЧЕСКИЕ МЕХАНИЗМЫ ПОДДЕРЖКИ

\author{
Петунова С.А., Захарова А.Н., Дулина Г.С. \\ ФГБОУ ВО «Чувашский государственныій университет имени И.Н. Ульянова», Чебоксары, \\ e-mail: petunova75@mail.ru
}

\begin{abstract}
Развитие молодежного предпринимательства стало особенно актуально в связи с тем, что позволяет решить проблему трудоустройства молодежи посредством самозанятости и способствует улучшению личностного роста и самореализации молодежи. В работе представлен анализ проблем безработицы и трудоустройства молодежи на рынке труда, действующих программ в области занятости населения, в том числе развития молодежного предпринимательства. Анализ исследований показывает, что молодежь активно стремится к организации собственного дела, но вместе с тем молодые предприниматели находятся в невыгодном положении по ряду направлений: отсутствие целостной системы организации предпринимательства, доступности финансового капитала и получения образования, навыков организации собственного дела и возможности получения профессионального консультирования и приобретения навыков. В качестве препятствий на пути реализации создания собственного дела у молодежи может рассматриваться психологическая неготовность к предпринимательской деятельности, отсутствие знаний и навыков, необходимых для ее осуществления. В рамках работы с молодежью помимо экономических механизмов поддержки будут эффективны мероприятия, связанные с психологической поддержкой: тренинги, направленные на формирование деловых и лидерских качеств, уверенности в себе, навыков конструктивного поведения на рынке труда и самомотивации; работа квалифицированных психологов по формированию психологических навыков и корректных экономических представлений, снятию психологических барьеров; система наставничества опытных бизнесменов. Организация программ поддержки молодежного предпринимательства посредством наставничества уже состоявшихся и эффективно действующих предпринимателей может послужить ролевой моделью на пути формирования предпринимательских установок и устранения страха риска; позволяет сформировать представления о реальной ситуации на рынке и наладить бизнес-контакты. Психологические меры поддержки возможны также в рамках образовательной среды через формирование и развитие мотивации к предпринимательской деятельности посредством привлечения успешных представителей бизнес-среды к участию в образовательном процессе и проведении производственной практики, мотивирование преподавателей на практическую направленность читаемых курсов, развитие предпринимательского мышления, создание бизнес-инкубаторов при образовательных учреждениях. Эффективная реализация программ поддержки молодежного предпринимательства должна комплексно сочетать меры по экономической и психологической поддержке, стать неотъемлемой частью научно-методического сопровождения предпринимательской деятельности на различных этапах становления молодого предпринимателя.
\end{abstract}

Ключевые слова: молодежное предпринимательство, Чувашская республика, безработица, трудоустройство выпускников, экономические и психологические меры поддержки

\title{
THE PROBLEM OF DEVELOPMENT OF YOUTH ENTREPRENEURSHIP: ECONOMIC AND PSYCHOLOGICAL MECHANISMS OF SUPPORT
}

\author{
Petunova S.A., Zakharova A.N., Dulina G.S.
}

Chuvash State University, Cheboksary,e-mail: petunova75@mail.ru

The development of youth entrepreneurship has become especially important in connection with the fact that it allows solving the problem of youth employment through self-employment and contributes to the improvement of personal growth and self-realization of youth. The paper presents an analysis of the problems of unemployment and youth employment in the labor market, existing programs in the field of employment, including the development of youth entrepreneurship. Analysis of studies shows that young people are actively striving to organize their own business, but at the same time, young entrepreneurs are at a disadvantage in a number of areas: the lack of a holistic system of organizing entrepreneurship, the availability of financial capital and education, the skills to organize their own business and the possibility of obtaining a professional sulting and acquiring skills. As obstacles to the implementation of creating their own business, young people can be considered psychological unpreparedness for entrepreneurial activity, lack of knowledge and skills necessary for its implementation. In the framework of work with youth, in addition to economic support mechanisms, measures related to psychological support will be effective: trainings aimed at building business and leadership qualities, self-confidence, constructive behavior skills in the labor market and self-motivation; the work of qualified psychologists in the formation of psychological skills and correct economic ideas, the removal of psychological barriers; mentoring system for experienced businessmen. The organization of youth entrepreneurship support programs through the mentoring of already established and effective entrepreneurs can serve as a role model for the formation of entrepreneurial attitudes and the elimination of fear of risk; allows you to create ideas about the real situation on the market and establish business contacts. Psychological support measures are also possible within the educational environment through the formation and development of motivation for entrepreneurial activity by attracting successful representatives of the business environment to participate in the educational process and conducting practical training, motivating teachers to practice the orientation of taught courses, developing entrepreneurial thinking, creating business incubators at educational institutions. Effective implementation of youth entrepreneurship support programs should comprehensively combine measures for economic and psychological support, become an integral part of the scientific and methodological support of entrepreneurial activity at various stages of the formation of a young entrepreneur.

Keywords: youth entrepreneurship, Chuvash Republic, unemployment, employment of graduates, economic and psychological support measures 
В «Концепции долгосрочного социально-экономического развития Российской Федерации на период до 2020 года» [1] подчеркивается, что российская экономика оказалась перед долговременными системными вызовами, отражающими как мировые тенденции, так и внутренние барьеры развития. В соответствии с данной Концепцией стратегической целью государства является достижение уровня экономического и социального развития, соответствующего статусу России как ведущей мировой державы XXI в., занимающей передовые позиции в глобальной экономической конкуренции и надежно обеспечивающей национальную безопасность и реализацию правовых прав граждан. Одним из таких системных вызовов стало возрастание роли человеческого капитала как основного фактора экономического развития, что актуализировало исследования в области психологии экономического поведения и сознания, психологии предпринимательства. Трансформация экономических отношений на современном этапе в России требует от населения самостоятельности и предприимчивости, активного экономического поведения, резко возросла важность предпринимательской деятельности. Развитие молодежного предпринимательства позволяет не только решить проблему трудоустройства молодежи посредством самозанятости, но и дает новые возможности для личностного роста и эффективной самореализации данной категории населения.

Цель исследования: анализ проблем безработицы и трудоустройства молодежи на рынке труда и поддержки и развития молодежного предпринимательства в России, выявление основных механизмов поддержки молодежного предпринимательства.

\section{Материалы и методы исследования}

Анализ справочно-статистических материалов органов статистики Российской Федерации, Чувашской Республики, документации Центра занятости населения г. Чебоксары, посвященных развитию предпринимательства на федеральном и региональном уровне, фактологического материала, содержащегося в материалах научных источников.

В работе использовался метод анализа научных источников по проблеме молодежного предпринимательства в России, а также анализ действующих программ поддержки молодежного предпринимательства (на примере Центра занятости г. Чебоксары)

\section{Результаты исследования и их обсуждение}

Действия органов власти в области занятости населения за последние годы привели к тому, что за прошедший 2018 г. в целом были созданы благоприятные усло- вия для ситуации на рынке труда. Уровень занятости населения, как и в предыдущие 2 года, был близок к отметке $66 \%$ от численности населения в возрасте 15-72 лет, а уровень безработицы обновил исторический минимум и составил $4,8 \%$ от численности рабочей силы, снизившись на 0,4 п.п. по сравнению с 2017 г. Согласно данным Росстата численность безработных в среднем за 2018 г. составила 3,7 млн человек. Это на 8\% меньше значения 2017 г. (4,0 млн человек). Уровень регистрируемой безработицы в целом по Российской Федерации впервые за всю историю наблюдений оказался ниже $1 \%$. В среднем за 2018 г. он составил $0,9 \%$ от численности рабочей силы в возрасте 15-72 лет (по данным Министерства труда и социальной защиты Российской Федерации 2018 г.) [2].

Достичь данных результатов позволили ряд мероприятий:

- разработка нормативной правовой и методической базы в сфере занятости населения;

- систематический мониторинг рынка рабочей силы и предложений работодателей;

- опережающее профессиональное обучение и профессиональная переподготовка работников организаций, находящихся под риском высвобождения;

- изменение механизма выплаты пособия по безработице, увеличение размера пособия по безработице и т.д.

Особо хочется отметить, что реализации мероприятий активной политики занятости населения, включая мероприятия по развитию трудовой мобильности, способствовали тому, что в органы службы занятости в 2018 г. было подано 3 508,4 тыс. заявлений о содействии в поиске подходящей работы, из них трудоустроено 2332,0 тыс. чел., или 66,5%. В 2018 г. приступили к профессиональному обучению и дополнительному профессиональному образованию 18,4 тыс. женщин, находящихся в отпуске по уходу за ребёнком до достижения им возраста трёх лет, завершили профессиональное обучение 18,2 тыс. женщин, в том числе путем профессиональной подготовки, переподготовки - 12,1 тыс. женщин, повышения квалификации - 6,1 тыс. женщин (по данным Министерства труда и социальной защиты Российской Федерации 2018 г.) [2].

В субъектах Российской Федерации, входящих в состав Северо-Кавказского федерального округа, в 2018 г. численность участников дополнительных мероприятий составила 8,1 тыс. чел. с учетом трудоустроенных в рамках программы по предпринимательству из числа незанятых граж- 
дан (1,8 тыс. чел.). Прошли опережающее обучение 4,4 тыс. чел., в том числе в организациях строительной отрасли 1,3 тыс. чел., в организациях курортно-туристического комплекса 0,8 тыс. человек, в организациях, реализующих социально-экономические проекты, 2,3 тыс. чел. В рамках мероприятия по стимулированию предпринимательской деятельности в целях создания новых рабочих мест выплату получили 894 работодателя, которые приняли на работу 1,8 тыс. незанятых граждан. С целью получения опыта работы для дальнейшего трудоустройства прошли стажировку 977 выпускников организаций высшего и среднего профессионального образования (по данным Министерства труда и социальной защиты Российской Федерации 2018 г.) [1]. В рамках реализации программы дополнительных льгот и гарантий лицам предпенсионного возраста, действующей с 1 января 2019 г., предпенсионер сможет получить дополнительное профессиональное образование в соответствии с востребованным в нынешнее время навыками и компетенциями [3].

Предложение по повышению в России пенсионного возраста высветило ряд социально-экономических вопросов, в том числе и вопрос соотношения на рынке труда молодых и более пожилых работников. В СМИ появилось большое количество материалов об огромной безработице молодежи в возрасте 15-24 лет: в июне 2018 г. численность безработных в России, оцененная по методологии Международной организации труда (далее - МОТ), составила 3,5 млн человек, при этом доля молодежи 15-24 лет в общей численности безработных была 22,8\%. Надо понимать, что безработными по методологии МОТ считаются люди, которые не имели работы, активно занимались ее поисками и были готовы приступить к работе в течение обследуемой недели. Важен тот факт, что численность молодежи в России на 2018 г. 14,2 млн, соответственно, безработица среди молодежи указанного возраста равняется 5,6\%. В данной возрастной группе находятся и школьники, которые ищут подработку на период летних каникул, и учащиеся СПО, и вузов, которые не имеют опыта работы, и в случае обучения по очной форме, либо ищут ее на период каникул, либо могут совмещать с учебой, но работая неполный рабочий день. В любом случае молодежь в случае обращения к работодателю может рассчитывать, как правило, на низко квалифицированный, рутинный и малооплачиваемый труд, либо их места могут быть заняты квалифицированными работниками, так как с позиции работодателя, они более социально ответственны и дисциплинированны [3].

После окончания вуза примерно 50\% выпускников, как показывает мониторинг трудоустройства молодежи Центра экономики непрерывного образования РАНХиГС, продолжают работать там, где они начали трудиться еще во время учебы [3].

В течение трех месяцев после окончания высших учебных заведений трудоустраиваются более 60-70\% выпускников, в течение года - почти $100 \%$. Как правило, выходят на рынок труда молодые люди либо по болезни, либо по семейным обстоятельствам (беременность, рождение детей и пр.), но в этом случае они не попадают под категорию безработных [3].

Успешность трудоустройства выпускников во многом обусловлена их конкурентоспособностью, которая зависит не только от объективных факторов, например востребованности профессии, но и оценки Я-конкурентоспособности молодых специалистов. Субъективная конкурентоспособность складывается как из личностных характеристик, например пол, возраст, профессиональных умений и навыков, особенностей характера личности, самооценки значимости себя как работника, а также общего уровня принятия себя как специалиста $[4,5]$.

В эмпирическом исследовании, проведенном на базе в ФГБОУ ВО «ЧГУ им. И.Н. Ульянова» в качестве основного метода использовалась специально разработанная анкета для оценки Я-конкурентоспособности выпускников вуза. По результатам исследования выпускников вуза 2014 г. разных специальностей в ФГБОУ ВО «ЧГУ им. И.Н. Ульянова» (химия и фармакология, управление качеством, психология, гражданское и промышленное строительство, машиностроение и информационно вычислительные технологии) хотят работать по специальности 73,21\%. Причинами препятствующими трудоустройству $41,77 \%$ считают отсутствие стажа, 22,38\% - недостаточную жизненную активность и 6,66\% - отсутствие вакансий. Свои шансы на трудоустройство 28,25\% оценивают высоко. По их мнению, им удастся найти работу быстро и без особых проблем. Более половины $(53,46 \%)$ считают, что для поиска работы им потребуется немного времени. Большинство выпускников проявляют интерес к предпринимательской деятельности, но начало карьеры предпочитают строить в работе по найму, объясняя это отсутствием опыта и практических навыков, отсутствием клиентской базы $[4,5]$.

Исследование мотивированности молодежи к предпринимательской деятельности 
показало, что заниматься предпринимательской деятельностью в ближайшее время планируют $28 \%$ молодых людей, причем у $19 \%$ из них родители имеют свой бизнес. $9 \%$ - это молодые люди из среднего класса, которые нацелены на предпринимательскую деятельность «как призвание и профессию». 51\% опрошенных хотя и высказывают позитивное отношение к предпринимательской деятельности, но не связывают ее напрямую с реальными жизненными планами. Для большинства опрошенных гарантия трудоустройства (не обязательно в области предпринимательства), обеспеченность жильем выше желания сделать карьеру в сфеpe предпринимательской деятельности. В целом лишь $28 \%$ связывают ближайшие жизненные и профессиональные планы с предпринимательской деятельностью [6].

Исследования показывают, что наиболее популярные бизнес-идеи среди молодежи, связаны со следующими секторами: потребительские товары - $18 \%$; наукоемкие технологии - $15 \%$; СМИ и индустрия досуга $11 \%$; туризм и гостиничный бизнес $-9 \%$; банки и финансы - $5 \%$; автомобилестроение - $5 \%$; строительство - $5 \%$; медико-биологические науки $-4 \%$; телекоммуникация $-4 \%$; электроэнергетика, коммунальное хозяйство, чистые технологии - 3\% [6].

Фактор профессионально-трудовой свободы является основополагающим для большинства молодых людей, так как возможность заработать и самореализоваться есть и в других видах профессиональной деятельности. В целом исследователи выделяют две группы факторов, способствующих успешному началу собственной предпринимательской деятельности:

- факторы окружающей среды («реальные перспективы развития страны» (31\%), «поддержка со стороны власти» $(28 \%))$;

- факторы личностного потенциала («открытие перспективной ниши развития предпринимательства» $(23 \%)$, «помощь со стороны родственников, друзей» (18\%)) [6].

Таким образом, для определенной части современной молодежи профессиональное будущее видится в области предпринимательства.

Распоряжение Правительства РФ от 29.11.2014 № 2403-р «Об утверждении основ государственной молодежной политики Российской Федерации на период до 2025 года» определяет молодежное предпринимательство как предпринимательскую деятельность граждан в возрасте до 30 лет, а также юридических лиц (субъектов малого и среднего предпринимательства), средний возраст штатных работников кото- рых, а также возраст руководителя не превышает 30 лет либо в уставном капитале которых доля вкладов лиц не старше 30 лет превышает $75 \%$ [7].

Развитие молодежного предпринимательства способствует формированию стабильной региональной экономики [8].

В настоящее время для поддержки молодежного предпринимательства появляется много государственных и республиканских программ, форм государственной поддержки малого и среднего бизнеса в регионе, получают развитие различные организационные формы бизнес-инкубаторов.

С декабря 2013 г. согласно приказу Министерства труда и социальной защиты Российской Федерации «Об утверждении федерального государственного стандарта государственной услуги по содействию самозанятости безработных граждан...» в регионах действуют программы оказания помощи начинающим предпринимателям, в рамках реализации которых по данным Центра занятости населения г. Чебоксары предполагается [9]:

1. Оценка степени готовности безработного гражданина к осуществлению предпринимательской деятельности, реализации самозанятости (сбор информации о безработном, информирование о предоставлении услуг, прохождение тестирования, анкетирования, по результатам которого принимается решение о целесообразности начала предпринимательской деятельности).

2. Организация подготовки бизнесплана и получения знаний и навыков, необходимых для осуществления предпринимательской деятельности, безработным гражданином, принявшим решение о целесообразности осуществления предпринимательской деятельности (предоставление безработному всесторонней информации по вопросам организации собственного дела, психологических аспектах предпринимательства и т.п., сопровождение процесса подготовки бизнес-плана, определение потребностей безработного в получении дополнительных профессиональных знаний, умений и навыков, необходимых для реализации бизнеса и возможность их получения, посредством обучения или прохождения стажировок у действующих предпринимателей.

3. Оказание гражданам, признанным в установленном порядке безработными, прошедшим профессиональное обучение или получившим дополнительное профессиональное образование по направлению органов службы занятости, финансовой помощи на подготовку документов для соответствующей государственной регистрации. 
Таким образом, стать участником программы могут официально зарегистрированные безработные граждане, обратившиеся с заявлением и предоставившие бизнес-план на рассмотрение комиссии. Получатель субсидии обязан как минимум 3 года заниматься заявленным бизнесом и вовремя отчитываться о расходах. Благодаря финансовой помощи, которую получили от Центра занятости населения г. Чебоксары в 2018 г., семь граждан стали предпринимателями. В прошлом году субсидия составляла 58800 руб. В 2019 г. участниками программы «Помощь начинающим предпринимателям» могут стать семь официально зарегистрированных в Центре занятости населения г. Чебоксары граждан, а размер субсидий составляет 96000 руб. Среди наиболее популярных начинаний - производство детского текстиля, мягкой мебели, спальных кроватей, предоставление услуг парикмахерскими и салонами красоты, предоставление услуг в сфеpe event-индустрии, деятельность в области фотографии и др.

Программа поддержки начинающих предпринимательство направлена не только на финансовую поддержку, но и на формирование у безработных профессиональных компетенций в области предпринимательской деятельности. Стремление начать собственное дело должно быть осознанным, хорошо спланированным шагом. Не каждый желающий способен к самозанятости не только из-за отсутствия стартового капитала, но также отсутствия ряда личностных качеств, опыта взаимодействия в данной сфере. Возможно, это обусловлено тем, что в большинстве случаев система образования готовит специалистов в первую очередь для государственного сектора экономики.

Чрезвычайно важным, по нашему мнению, является то, что помимо экономической, в рамках работы с молодежью оказывается и психологическая поддержка: тренинги, направленные на формирование деловых и лидерских качеств, уверенности в себе, навыков конструктивного поведения на рынке труда и самомотивации, проводящихся на базе Центра занятости населения г. Чебоксары [9]. Данный опыт ценен для более широкого внедрения в существующие программы поддержки молодежного предпринимательства, где зачастую недостаточно раскрыт психологический компонент, не ведется целенаправленная работа по психологическому формированию качеств молодых, юных и потенциальных предпринимателей.

Исследования показывают, что молодежь активно стремится к организации собственного дела, но вместе с тем моло- дые предприниматели находятся в невыгодном положении по ряду направлений: отсутствие целостной системы организации предпринимательства, доступности финансового капитала, доступности получения образования, навыков организации стартапов и возможность получения профессионального консультирования и приобретения навыков у успешных бизнесменов. Ряд исследований указывают на то, что организация доступных сетей, объединение единомышленников и введение наставничества в молодежной бизнес-среде дает возможность значительно снизить указанные выше барьеры [10].

В качестве психологических мер по поддержке молодежного предпринимательства может выступать также внедрение и использование в существующих и вновь создаваемых программах системы наставничества опытных бизнесменов для молодых предпринимателей - это может послужить живым примером, ролевой моделью для формирования эффективных предпринимательских установок, снятия некоторых психологических барьеров, страха риска; позволяет сформировать корректные экономические представления о реальной ситуации на рынке, помочь наладить бизнес-контакты [11].

Психологические меры поддержки возможны также в рамках образовательной среды через формирование и развитие мотивации к предпринимательской деятельности посредством привлечения успешных представителей бизнес-среды к участию в образовательном процессе и проведении производственной практики, мотивирование преподавателей на практическую направленность читаемых курсов, развитие предпринимательского мышления, создание бизнес-инкубаторов при образовательных учреждениях.

\section{Выводы}

Проведенный анализ современного состояния проблемы занятости населения показал, что одним из эффективных путей решения проблем трудоустройства молодежи на рынке является развитие молодежного предпринимательства. Анализ исследований, посвященных намерениям выпускников вуза, показывает, что достаточно большая часть будущих специалистов проявляют интерес к предпринимательской деятельности, но на пути реализации создания собственного дела может стоять психологическая неготовность к данному виду деятельности, отсутствие знаний и навыков, необходимых для осуществления предпринимательской деятельности. Экономико-психологическая поддержка наиболее 
эффективно может вестись через внедрение и использование в существующих и вновь создаваемых программах поддержки молодежного предпринимательства, проводимых силами квалифицированных психологов, тренинговых программ по формированию психологических навыков и корректных экономико-психологических представлений, снятию психологических барьеров; использование системы наставничества опытных бизнесменов в качестве ролевой модели для молодых предпринимателей.

Эффективная реализация программ поддержки молодежного предпринимательства должна комплексно сочетать механизмы по экономической и психологической поддержке, которые должны стать неотъемлемой частью научно-методического сопровождения предпринимательской деятельности на различных этапах становления молодого предпринимателя.

Исследование выполнено при финансовой поддержке РФФИ и Чувашской Республики в рамках научного проекта № 19-413$210007 p \_a$.

\section{Список литературы}

1. Распоряжение Правительства РФ от 17.11.2008 № 1662-р (ред. от 28.09.2018) «О Концепции долгосрочного социально-экономического развития Российской Федерации на период до 2020 года». [Электронный ресурc]. URL: http:// static.government.ru/media/ files/aaooFKSheDLiM99HEcyrygy tfmGzrnAX.pdf (дата обращения: 19.09.2019).

2. Уточненный годовой отчет Министерства труда и занятости за 2018 год. [Электронный ресурс]. URL: https:// rosmintrud.ru/uploads/editor/89/3a/У точненный годовой отчет за 2018 год 23.04.2019.docx (дата обращения: 19.09.2019).
3. Молодежная безработица в России - сколько, почему и оправдана ли паника [Электронный ресурc]. URL: https:// vogazeta.ru/articles/2018/11/6/analitycs/4451 molodezhnaya_ bezrabotitsa_v_rossii_skolko_pochemu_i_opravdana_li_panika (дата обращения: 19.09.2019).

4. Петунова С.А., Григорьева Н.В. Психологическое сопровождение адаптации студентов к условиям рынка труда // Проблемы современного педагогического образования. 2016. № 51-5. С. 568-576.

5. Петунова С.А. Исследование уровня самооценки конкурентоспособности студентов вуза // Качество и инновации в XXI веке: материалы 12-й Международной научнопрактической конференции. 2014. С. 154-159.

6. Паламарчук О.Н. Исследование мотивированности молодежи к предпринимательской деятельности // Альманах современной науки и образования. Тамбов: Грамота, 2013. № 11 (78). С. 122-126

7. Распоряжение Правительства РФ от 29.11.2014 № 2403-p «Об утверждении основ государственной молодежной политики Российской Федерации на период до 2025 года» [Электронный ресурс]. URL: www.consultant. ru/document/cons doc LAW 171835/ (дата обращения: 19.09.2019).

8. Дмитриева Е.А., Широкова Е.А. Опыт и перспективы участия вузов в развитии молодежного предпринимательства в регионе// Академическая публицистика. Изд-во Общество с ограниченной ответственностью «Аэтерна», 2018. С. 101-106.

9. Центр занятости населения г. Чебоксары [Электронный pecypc]. URL: gov.cap.ru/SiteMap.aspx?gov id=667\& $\mathrm{id}=2799163 \&$ title=Sodejstvie_samozanyatosti_bezrabotnih grazhdan (дата обращения: 19.09.2019).

10. Исследование воздействия добровольного бизнес-наставничества на молодых предпринимателей // AHO «Международный форум лидеров бизнеса» (IBLF Russia) и ООО «Институт наставничества» [Электронный pecypc]. URL: https://youthbusinessrussia.org/upload/ iblock/663/issledovanie-vozdeystviya-dobrovolnogo-biznesnastavnichestva-na-molodykh-predprinimateley.pdf/ (дата обращения: 19.09.2019).

11. Van Auken, Howard Fry, Fred L., Stephens Paul. The influence of role models on entrepreneurial intentions. Journal of developmental entrepreneurship Том: 11 Вып. 2. Р. 157-167. DOI: $10.1142 / \mathrm{S} 1084946706000349$. 